\title{
Importance of clothing removal in scalds
}

\author{
Edgar YK Lau *, Yvonne YW Tam, TW Chiu
}

This article was published on 26 Feb 2016 at www.hkmj.org.

\section{A B S T R A C T}

Objective: To test the hypothesis that prompt removal of clothing after scalds lessens the severity of injury.

Methods: This experimental study and case series was carried out in the Burn Centre of a tertiary hospital in Hong Kong. An experimental burn model using Allevyn (Smith \& Nephew Medical Limited, Hull, England) as a skin substitute was designed to test the effect of delayed clothing removal on skin temperature using hot water and congee. Data of patients admitted with scalding by congee over a 10-year period (January 2005 to December 2014) were also studied.

Results: A significant reduction in the temperature of the skin model following a hot water scald was detected only if clothing was removed within the first 10 seconds of injury. With congee scalds, the temperature of the skin model progressively increased with further delay in clothing removal.
During the study period, 35 patients were admitted with congee scalds to our unit via the emergency department. The majority were children. Definite conclusions supporting the importance of clothing removal could not be drawn due to our small sample size. Nonetheless, our data suggest that appropriate prehospital burn management can reduce patient morbidity.

Conclusions: Prompt removal of clothing after scalding by congee may reduce post-burn morbidity.

\section{Hong Kong Med J 2016;22:152-7 \\ DOI: 10.12809/hkmj144476}

EYK Lau *, MB, BS, FHKAM (Surgery)

YYW Tam, MB, ChB, MRCS (HKICSC)

TW Chiu, BMBCh (Oxford), FRCS (Glasgow)

Department of Surgery, Prince of Wales Hospital, Shatin, Hong Kong

* Corresponding author: lyk685@ha.org.hk

\section{New knowledge added by this study}

In hot water scalds, immediate clothing removal may lead to less severe injury.

In congee scalds, severity of injury can potentially be reduced with earlier removal of clothing.

- Adequate post-injury first aid with water in congee scalds may lower the chance of requiring surgical intervention.

Implications for clinical practice or policy

- Parents should be educated about scald prevention as it is prevalent in the paediatric population.

- It should be emphasised to the general public that immediate clothing removal, along with first aid by running cool water over the burn for 20 minutes within the first 3 hours of injury, could potentially reduce the severity of scald.

- Frontline medical staff should be aware of the importance of prehospital burn management so that relevant questions can be raised during the initial hospital admission.

\section{Introduction}

In Hong Kong, as in most developed countries, one of the most common types of burn injury that requires hospital admission is scald. If we view a scald as a 'contact burns due to a liquid', the severity of burn injury will be a function of starting temperature, contact time, and the thermal capacity of the causative agent. In a previous study performed in our centre, it was hypothesised that both viscosity and thermal capacity of the agent were important factors in prolonging heat exposure of the skin. ${ }^{1}$ Patients who were scalded by congee (a popular local dish where rice with excess water is simmered until a porridge-like mixture is formed) were more likely to require surgery than those scalded by hot water $(31 \%$ vs $14 \%$, respectively). ${ }^{1}$ This may be partly explained by congee's greater thermal capacity (causing more effective heat transfer) and viscosity (prolonging contact time).

In order to minimise the severity of burn injury, it is essential that effective first-aid measures be properly taught to the public. The two basic principles are to stop the burning process and to cool the burn wound. As patients are usually wearing clothes and underwear at the time of scalding, the most effective way to achieve the first objective is to remove the involved clothing as quickly as possible. For many reasons, however, this straightforward act is sometimes not performed in a timely manner (eg scald occurring in a restaurant where a patron is too embarrassed to take off his/her clothing or simple ignorance of first aid). It is in this context 
that a simple model was designed in an attempt to demonstrate the importance of prompt clothing removal after scalding has occurred.

\section{Methods}

In the first part of our study, the effect of delayed clothing removal on skin temperature was assessed using our experimental burn model. As in our centre's previous study, a piece of Allevyn foam dressing (Smith \& Nephew Medical Limited, Hull, England) served as our skin model. It was placed on a metal plate above a heated water bath (JP Selecta, Barcelona, Spain) until its surface temperature reached $34^{\circ} \mathrm{C}$ when measured using the Raytek noncontact thermometer (Raytek Corporation, Santa Cruz [CA], US) $1 \mathrm{~cm}$ above the centre, in an attempt to simulate 'skin temperature'. Cotton underwear was then placed on top of the Allevyn dressing. The scalding agents (hot water and congee) were boiled to $88^{\circ} \mathrm{C}$ and poured onto the model. The underwear was then removed at various times following the 'injury' (10, 20, 30, 60, and 120 seconds). The temperature of the Allevyn was immediately measured at the aforementioned position by the same observer starting from the moment of clothing removal and every 10 seconds thereafter for 2 minutes. The same procedure was repeated 3 times for each time interval, and the mean value was taken as the final data point. Standard cooling curves were subsequently plotted using these average data points along with calculated standard deviations.

In the second part, all patients admitted to our unit via the emergency department with scalding by congee over a 10-year period (January 2005 to December 2014) were first retrospectively identified from our hospital's computer records. Clinical notes were physically traced in order to examine the admission details as well as subsequent management of the patients.

\section{Results}

The results of our experimental burn model are shown in Figures 1 and 2. The temperature of the Allevyn partly reflected the amount of heat transferred from the causative agent. A higher cooling curve translated to a higher skin temperature (hence higher potential injury). Examination of the cooling curves revealed a difference in the behaviour of hot water and congee. With hot water, the 10-second cooling curve was lower than its counterparts (the 20-, 30-, 60-, and 120-second cooling curves) that essentially lie along the same curve above. With congee, the cooling curves appeared to lie progressively higher with further delay in clothing removal-the 30- and 60second cooling curves were in a significantly higher position compared with the 10- and 20-second cooling curves, while the 120 -second cooling curve

\section{湯傷後脫除衣物的重要性}

劉英傑、譚亦媛、趙多和

目的：測試璗傷後迅速脱除衣物有助減低受傷程度這個假設。

方法：這實驗研究及病例系列於香港一間提供第三層醫療服務的燒傷 中心內進行。利用以Allevyn為皮膚代替品的模擬燒傷模型在被熱水及 粥「湯傷」後, 測試延遲脱除衣物會如何影響皮膚温度; 研究並回顧 在 2005 年1月至 2014 年 12 月十年間被料䔽傷而需要入院治療的病人紀 錄。

結果：如被熱水湯傷後可在 10 秒內脱除衣物的話, 模擬燒傷模型內 的皮膚温度明顯降低。被粥湯傷後, 延遲脱除衣物將會令模擬燒傷模 型內的皮膚温度逐步上升。在研究的十年期間, 有 35 名病人因被粇腹 傷須由急症室轉送入院治療, 大部份病人均為兒童。由於病人數目太 少, 我們未能得出明確的結論以支持湯傷後迅速脱除衣物的重要性這 假設。不過, 數據仍顯示假如病人抵達醫院前能正確處理湯傷, 可減 少湯傷為病人所帶來的傷害。

結論：被䉼璗傷後迅速脱除衣物或有助減少病人燙傷後的受傷程度。

was higher than that of 30 and 60 seconds.

During the study period, 35 patients were admitted (21 males, 14 females) for scalding by congee. Of note, two paediatric patients were admitted to the Intensive Care Unit (ICU) for initial resuscitation due to the extent of their burns (16\% and $20 \%$ of total body surface area [TBSA]) and one patient was discharged against medical advice after being admitted for 1 day. The demographic distribution, percentage of TBSA burnt, and length of hospital stay are shown in Table 1. On average, our unit admitted two to four cases per year except in 2010 when there were seven cases. Although most of these congee scalds were relatively minor as evidenced by the small mean percentage of TBSA involved and a mean hospital stay of approximately 11 days, more than two thirds of patients were children. Table 2 shows the statistics for clothing removal/ first-aid measures and the subsequent management. While most of our patients received some form of first aid, it was found that the act of clothing removal was not documented in the majority (27/35) of cases. Despite an extended review period, it is recognised that the sample size remains small. Consequently, only descriptive statistics could be shown and a formal statistical analysis could not be conducted for this retrospective review. Nonetheless, those patients who received first aid or in whom clothing was removed (or both) did seem to fare better than those without.

\section{Discussion}

This was a preliminary study of the potential relationship between the time of clothing removal 



and depth of scald burns. While 'cooling the burn offending agent with the skin should be minimised. wound' is an important step in the first-aid process, A cooling study was performed by our centre in it must be recognised that 'stop the burning process' 2006 to examine the cooling curves of different should take precedence in order to maximise the food/drinks. Of seven common agents examined benefit of first aid. To this end, the contact time of the for their rate of cooling, congee cooled significantly 
TABLE I. Summary of demographic data of patients with congee scalds (January 2005 to December 2014)

\begin{tabular}{|c|c|}
\hline Demographics & Data \\
\hline \multicolumn{2}{|l|}{ By gender (No. of patients) } \\
\hline Male & 21 \\
\hline Female & 14 \\
\hline \multicolumn{2}{|l|}{ By year (No. of patients) } \\
\hline 2005 & 2 \\
\hline 2006 & 4 \\
\hline 2007 & 2 \\
\hline 2008 & 4 \\
\hline 2009 & 4 \\
\hline 2010 & 7 \\
\hline 2011 & 4 \\
\hline 2012 & 3 \\
\hline 2013 & 3 \\
\hline 2014 & 2 \\
\hline \multicolumn{2}{|l|}{ Age (years) } \\
\hline Mean & 18.4 \\
\hline Range & $0.5-78$ \\
\hline Median & 2 \\
\hline Age $\leq 16$ (range: $0.5-5$ ) & 24 \\
\hline Age $\leq 2$ & 18 (male:female = 12:6) \\
\hline Age $>16$ & 11 \\
\hline \multicolumn{2}{|l|}{$\%$ Total body surface area } \\
\hline Mean & 5.3 \\
\hline Range & $0.5-20$ \\
\hline Median & 4 \\
\hline No. of patients with major burns & 3 \\
\hline \multicolumn{2}{|l|}{ Length of stay (days) } \\
\hline Mean & 10.9 \\
\hline Range & $1-38$ \\
\hline Median & 9 \\
\hline
\end{tabular}

slower compared with the other agents (eg tea, coffee, noodles, etc). ${ }^{1}$ It was also shown that a higher percentage of patients required surgery if scalded by congee compared with hot water. As congee is a common dish for children in Hong Kong from which scalds could lead to greater morbidity, congee was specifically selected for further investigation.

We showed that delay in clothing removal could increase the severity of scald burns by congee as demonstrated by the increased temperature in our skin model when clothing removal was delayed. The experiment did not persist beyond a delay of 120 seconds since clothing would generally be removed within that time or not at all.

Hot water was first examined as a 'control' compared with congee. In our results, the cooling
TABLE 2. Presence of clothing removal/first-aid measures and management modalities

\begin{tabular}{|c|c|}
\hline & No. of patients \\
\hline \multicolumn{2}{|l|}{ Was clothing removal performed? } \\
\hline \multicolumn{2}{|l|}{ Not recorded } \\
\hline Not recorded but required removal & 17 \\
\hline $\begin{array}{l}\text { Not recorded but did not require } \\
\text { removal (areas such as face, hands) }\end{array}$ & 10 \\
\hline \multicolumn{2}{|l|}{ Recorded } \\
\hline Removed & 6 \\
\hline Not removed & 2 \\
\hline \multicolumn{2}{|l|}{ Presence of first aid } \\
\hline Yes & 27 \\
\hline By cool water & 15 \\
\hline No & 5 \\
\hline Not recorded & 3 \\
\hline \multicolumn{2}{|l|}{ Management modalities* } \\
\hline Overall & 34 \\
\hline Conservative & 26 \\
\hline Surgery (\% requiring surgery) & $8(24 \%)$ \\
\hline \multicolumn{2}{|l|}{ With clothing removal } \\
\hline Conservative & 5 \\
\hline Surgery & 1 \\
\hline \multicolumn{2}{|l|}{ Without clothing removal } \\
\hline Conservative & 1 \\
\hline Surgery & 1 \\
\hline \multicolumn{2}{|l|}{ With first aid } \\
\hline Conservative & 22 \\
\hline Surgery & 4 \\
\hline \multicolumn{2}{|l|}{ With first aid by cool water } \\
\hline Conservative & 13 \\
\hline Surgery & 1 \\
\hline \multicolumn{2}{|l|}{ With first aid by other means } \\
\hline Conservative & 9 \\
\hline Surgery & 3 \\
\hline \multicolumn{2}{|l|}{ Without any first aid } \\
\hline Conservative & 1 \\
\hline Surgery & 4 \\
\hline \multicolumn{2}{|l|}{ With both clothing removal and first aid } \\
\hline Conservative & 5 \\
\hline Surgery & 0 \\
\hline
\end{tabular}

* Excluded one patient who was discharged against medical advice

curves of 20,30,60, and 120 seconds essentially lay along the same curvature while the 10-second cooling curve was significantly lower. This implies that if clothing removal occurs within the first 10 seconds, the surface temperature of our skin model would be significantly lower at all subsequent time 
points; thus in hot water scalds, immediate clothing removal may prove to be the most beneficial.

On subsequent examination of the effect of congee, the cooling curves behaved differentlythere appeared to be a stepwise progression from the 10 - and 20-second curves to the 30 - and 60-second curves, and then finally to the 120-second curve. Observation of the error bars showed that the 10and 20-second curves did not differ significantly and this also applied to the 30- and 60-second curves. The 120-second curve generally lay significantly above the rest; therefore, it appears that delay in clothing removal significantly affected the surface temperature of our skin model-removing it within the first 20 seconds may lead to a less-severe injury compared with a 30 - to 60-second delay, which in turn is better than a 2-minute delay.

At the time points between 120 and 140 seconds where all the curves have overlapping temperature measurements, one is able to observe that there are three distinct 'tiers' (10/20, 30/60, 120 seconds). In our model, heat was transferred to the Allevyn with the garment initially acting as a 'barrier' since the underwear was removed before the congee could soak through, resulting in a lower temperature detected. By increasing the time interval, the garment increasingly acted as a 'reservoir' for heat as the congee gradually soaked through. Due to the greater thermal capacity and viscosity of congee compared with water, the temperature of the entire 'congeeunderwear-Allevyn complex' was maintained with more heat being transferred to the Allevyn for the same given period, resulting in a higher temperature detected. Overall, our findings corroborate our hypothesis that with a viscous agent such as congee, the severity of scald burns could potentially be reduced with earlier removal of clothing as evidenced by lower temperatures detected in our skin model.

Although our experimental study did succeed in demonstrating effects in our skin model, the ideal model for this study would be human skin (eg cadaveric or surgically excised) but it is rather difficult to source in practice. For the sake of scientific reproducibility, Allevyn was used instead (a bilayer dressing material with an outer waterproof layer analogous to the epidermis along with an inner absorbent sponge layer). Although Allevyn does not exactly mimic the 'in-vivo' behaviour of human skin per se, this model allows the opportunity for comparative study. Another potential improvement of our model is to set up a thermometer to measure the skin model's temperature underneath the surface so that temperature can be tracked while clothing is still in place. In this experimental model, we were only able to measure the temperature after the garment was removed. Having continual temperature monitoring would enable us to plot 'complete' curves starting from 0 second onwards for all five time intervals, and the temperature change both before and after clothing removal could be more accurately depicted. In an early study by Moritz and Henriques, ${ }^{2}$ porcine skin was found to bear a remarkable resemblance to human skin. If the experiment can be repeated with porcine skin along with improved accuracy of temperature measurement (ie setting up a thermometer intradermally within the porcine skin), the validity of our conclusions may be strengthened. Nonetheless, this experimental study lends support to the notion that timely clothing removal before first-aid application may reduce the severity of burn injury.

The paediatric population (especially those under the age of 2 years) is particularly susceptible to scalds with a male preponderance. ${ }^{3-5}$ This age-group is particularly vulnerable as it is an age of great curiosity about the environment (hence the tendency to grab/ tip over things) but limited motor development does not allow a child to move away from danger, such as a falling bowl of congee. It is also compounded by the fact that children have relatively thinner skin and this results in more significant injuries. Our statistics from this congee scald review do not deviate much from our centre's previous experience: slightly over $50 \%$ of our patients were aged 2 years or younger with a male predominance, and 24 out of 35 patients were within the paediatric age-group.

It seems almost intuitive that clothing should be removed as soon as possible whenever a scald burn is sustained. This may not necessarily be so. In a recent UK study where parents were interviewed and asked about first-aid measures they would provide for a child with a large scald, $61 \%$ of parents failed to state that clothes should be stripped and several thought that it would cause further skin damage. ${ }^{6}$ The question of whether removing clothing would cause further skin damage is commonly asked by parents of paediatric burn patients admitted to our unit.

In our retrospective review, analysis of the efficacy of clothing removal was hindered because such action was not recorded in the majority of cases (27 out of 35). The location of burns was further studied: in 10 of these 27 cases, injury occurred over an exposed area (eg face and hands), while the remaining 17 cases could have benefited from clothing removal. In six of eight patients where clothing was removed, the exact timing was not documented. Such lack of documentation demonstrates the benefit of education about prehospital treatment for both the public and frontline medical staff. An increased awareness of correct prehospital treatment of burns would mean relevant questions are asked during history taking, and this would facilitate proper documentation and subsequent patient management. As mentioned in the Results section, our sample size did not permit 
any meaningful statistical analysis to be carried out pertaining to the potential usefulness of early clothing removal in reducing morbidity from scalds. Nonetheless, it appeared that those patients who had clothing removed fared quite well. One exception was a 50-year-old man with a relatively larger scald (TBSA, 13\%) involving the face/neck/chest/bilateral upper limbs who eventually required skin grafting.

After the burning process is stopped, the next logical step is to cool the burn by applying first aid. Ideally, first aid for burns should provide pain relief and reduce potential morbidity associated with the injury. Although many first-aid treatments to cool burns have been studied, the application of cold water has the strongest supporting evidence. Currently, an 'adequate' first aid is defined as 20 minutes of running tap water over the burn within the first 3 hours of injury. ${ }^{7}$ Apart from removing heat energy from the damaged tissue, the benefits of cooling continue and include decreased oedema formation, preservation of dermal perfusion, decreased inflammatory response, and improved wound healing. ${ }^{8,9}$ Regrettably, our centre's previously published paper showed that first aid was applied only to half of our paediatric patients. ${ }^{5}$ In our current review, although 27 patients received some form of first aid, only 15 (43\%) patients received cool-water treatment of variable duration. The duration of first aid with cool water was either not recorded or fell short of the recommended 20 minutes. This state of affairs is certainly unsatisfactory and more public education is warranted.

Our data once again do not enable formal statistical analysis, and a number of factors such as percentage of TBSA burnt and depth of burn would affect the eventual outcome of our patients. Nonetheless, it does appear that those who received first aid required fewer surgeries. Detailed analysis of those who received no first aid revealed that none of the burns was classified as major even though four out of eight patients underwent skin grafting. In patients who received cool water as first aid, only one needed surgery-a 14-month-old boy with a TBSA of $13.5 \%$ burnt involving the left flank and bilateral lower limbs. In patients who received other types of first aid, three required surgeries (one of whom had a major burn and required ICU admission). Of note, for patients in whom clothing was removed and first-aid measures applied, all were managed conservatively. Although definite conclusions from our data cannot be drawn, clothing removal and first aid do seem to have beneficial effects, especially in smaller burns that constitute most of our case load. It is our hope that with better medical documentation and education of our frontline staff, the quality of our future data can be enhanced with a view to facilitate formal data analysis.

Before a simple and effective message can be delivered to the public about post-burn prehospital management, it is equally important to consider the local food characteristics. For instance, the population of Hong Kong may find it easier to relate burns to congee or cup noodle than burns to coffee. Since half of our paediatric burn patients received no first aid upon admission, simply emphasising the importance of 'stop the burning process' may reduce potential morbidity. Our experimental skin model showed that earlier clothing removal postburn reduces skin temperature and thus beneficial. Although our retrospective review was unable to reflect any concrete statistical results, it was certainly suggestive of the potential usefulness of proper prehospital management. Last but not least, the financial cost of managing acute uncomplicated minor paediatric scalds is significant (including hospital beds, theatre visits, dressings, medications etc). This is an important social and economic issue since burns sustained by children often require many years of follow-up for scar management and psychosocial support. ${ }^{10}$ If preventive measures fail and accidents occur, it is in the best interests of the public to understand how to minimise morbidity.

\section{References}

1. Chiu TW, Ng DC, Burd A. Properties of matter matter in assessment of scald injuries. Burns 2007;33:185-8.

2. Moritz AR, Henriques FC. Studies of thermal injury: II. The relative importance of time and surface temperature in the causation of cutaneous burns. Am J Pathol 1947;23:695-720.

3. Ray JG. Burns in young children: a study of the mechanism of burns in children aged 5 years and under in the Hamilton, Ontario Burn Unit. Burns 1995;21:463-6.

4. Dewar DJ, Magson CL, Fraser JF, Crighton L, Kimble RM. Hot beverage scalds in Australian children. J Burn Care Rehabil 2004;25:224-7.

5. Tse T, Poon CH, Tse KH, Tsui TK, Ayyappan T, Burd A. Paediatric burn prevention: an epidemiological approach. Burns 2006;32:229-34.

6. Graham HE, Bache SE, Muthayya P, Baker J, Ralston DR. Are parents in the UK equipped to provide adequate burns first aid? Burns 2012;38:438-43.

7. First aid. Australian and New Zealand Burn Association. Available from: http://anzba.org.au/care/first-aid/. Accessed Feb 2016.

8. Cuttle L, Pearn J, McMillan JR, Kimble RM. A review of first aid treatments for burn injuries. Burns 2009;35:76875.

9. Wright EH, Harris AL, Furniss D. Cooling of burns: mechanisms and models. Burns 2015;41:882-9.

10. Griffiths HR, Thornton KL, Clements CM, Burge TS, Kay AR, Young AE. The cost of a hot drink scald. Burns 2006;32:372-4. 